\title{
Usus pauper e poesia no Guidado com a casa comum
}

Recebido: 01/11/2016. Aprovado: 15/11/2016.

\section{Edelcio Ottaviani*}

Resumo: O presente artigo articula três elementos fortemente associados à temática central da Encíclica Laudato Si, a segunda de autoria do Papa Francisco. São eles: o cuidado com a casa comum, o usus pauper e a linguagem poética. Sobre a temática do cuidado e sua relação com a espiritualidade ecológica, partimos dos estudos foucaultianos do "cuidado de si" na antiguidade clássica; no que se refere à noção do usus pauper e ao problema da conversão, aludiremos aos estudos do termo latino e sua polêmica no contexto medieval, trabalhada por Giorgio Agamben (1942); por último, baseando-nos em uma das estrofes do Cântico das Criaturas, procuraremos mostrar como a linguagem poética pode reativar a nossa sensibilidade e despertar mais diretamente a razão de nos voltarmos para o cuidado com a casa comum e, mais especificamente, com o elemento água.

Palavras-chave: Usus pauper. Cuidado do outro. Linguagem poética

\begin{abstract}
The present article articulates three elements that we believe to be strongly associated to the central theme of the Encyclical Letter "Laudato Si", the second one by Pope Francis. They are: the care for our common home, the "usus pauper" and poetic language. With reference to the care theme and its relationship to ecological spirituality, we start from the Foucaultian studies of "care of oneself "in classical antiquities; in what concerns the notion of "usus pauper "and the problem of conversion we will refer to the studies of the term and its polemics in the medieval contexts, worked by Giorgio Agamben (1942); finally, with basis on one of the stanzas of the "Canticle of the Creatures", we will try to show how poetic language can reactive our sensibility and awaken more directly the reason for us to turn to the care for our common home and more specifically towards the water element.
\end{abstract}

Keywords: Usus pauper. Care towards the other. Poetic language.

* Doutor em Filosofia (UCL) e Mestre em Teologia (PUCSP). Professor do Departamento de Teologia Fundamental da Faculdade de Teologia PUCSP. Reitor do Centro Universitário Assunção - UNIFAI. 


\section{Introdução}

Dos seis capítulos que compõem a terceira encíclica do pontificado de Francisco, este ensaio encontra sua inspiração no capítulo II, dedicado ao Evangelho da Criação em sua relação com a linguagem e atitudes proféticas de Francisco de Assis. Neste primeiro documento pontifício voltado exclusivamente para a preservação do meio ambiente, o Papa se volta para o cuidado com a casa comum, a mãe Terra, toma a peito a expressão do Canto das Criaturas e a associa à preocupação com o meio ambiente, já esboçada por três de seus antecessores ${ }^{1}$. Abre-se assim um leque de reflexões, sobretudo no campo da espiritualidade. É o que faz Francisco no Capítulo VI, dedicado à educação e à espiritualidade ecológica.

Nas páginas seguintes, procuraremos apresentar três elementos que estão fortemente associados à temática central da encíclica ecológica: cuidado com a casa comum, o usus pauper e linguagem poética. Para o desenvolvimento do primeiro tópico retomamos alguns aspectos sobre a temática do cuidado e sua relação com a espiritualidade, a partir dos estudos foucaultianos do "cuidado de si"; no segundo tópico, ao tratar do problema da conversão, aludiremos à noção do usus pauper e sua polêmica no contexto medieval, trabalhada por Giorgio Agamben (1942) em A Altissima pobreza; por último, baseando-nos em uma das estrofes do Cântico das Criaturas, procuraremos mostrar como a linguagem poética pode reativar a nossa sensibilidade e despertar mais diretamente a razão de nos voltarmos para o cuidado com a casa comum e mais especificamente com o elemento água. ${ }^{2}$

"Laudato Si" é o segundo documento cuja autoria é atribuída exclusivamente ao papa Francisco. O primeiro, Lumen Fidei, publicado em 29 de junho de 2013, já havia sido esboçado por seu antecessor, Bento XVI, com vistas a encerrar o Ano da Fé. Sendo o terceiro da tríade reverenciando as virtudes teologais (Deus caritas est, Spe Salvi), Lumen Fidei, entende "agrupar-se a quanto Bento XVI escreveu nas Cartas encíclicas sobre a caridade e a esperança", diz o papa Francisco (LF, 7), que acrescenta: "Ele [o papa Bento XVI] tinha já quase completado uma primeira tessitura de Carta encíclica sobre a Fé. Sou-lhe profundamente grato por isso, e assumo seu precioso trabalho, acrescentando ao texto alguns ulteriores contributos" (Ibidem)" (OTTAVIANI, Edelcio. Doença, convalescença e ascese, o que suporta um corpo: notas sobre o cuidado com a mãe Terra, nossa casa comum. Revista de Cultura Teológica, São Paulo, ano XXIV, n. 87, jan/jun 2016, p. 210).

2 Este estudo foi realizado com a colaboração do trabalho de Iniciação Científica de Thamirez Lutaif Lopes (PUCSP), intitulado "Ecologia e Resistências: a contemporaneidade de Francisco de Assis em sua relação com o elemento água". A contribuição de Thamirez se faz sentir, particularmente, na terceira parte deste artigo, relacionada à linguagem poética, na qual ela responde ao desafio de traduzir, a partir da tradição teológica, os quatro elementos apontados por Francisco de Assis referentes ao elemento água: utilidade, humildade, preciosidade e castidade. 


\section{Cuidado com a casa comum}

Leonardo Boff (1938), ao tratar da espiritualidade ecológica, nos fala que as pessoas, ao se verem distintas da natureza, tendem a dominá-la e a interferir em seu sistema sem pensar nas consequências nefastas dessa intervenção. Segundo ele, esquecer essa ligação foi um engano do racionalismo ${ }^{3}$. Michel Foucault, em as Palavras e as Coisas, reverberando as críticas de Heidegger à sociedade tecnológica, nos mostra que, depois de Descartes, tudo o que cerca o sujeito de conhecimento foi visto como objeto passível de ser classificado, calculado e dominado ${ }^{4}$. Com Descartes, iniciou-se também a batalha da razão na análise e apreensão de tudo aquilo que nos cerca. Depois dele, a especialização empreendeu uma curva ascendente. Pouco a pouco, o conhecimento se viu compartimentado, e as disciplinas voltaram-se para si, numa ampliação cada vez maior do seu campo de saber, sem ter a preocupação com as consequências dessa especialização em outras áreas do conhecimento. No Brasil, no campo da engenharia civil, vimos, por exemplo, a construção de imensas hidrelétricas na década de setenta, alheias aos impactos ambientais. Foi preciso que biólogos de todas as partes do mundo dessem o grito de alarme para que começássemos a relacionar a crescente escalada da extinção de certas espécies da fauna e da flora com a corrida tecnológica e a avidez da sociedade de consumo. A humanidade pouco a pouco percebeu que era preciso passar de uma visão compartimentada para uma visão holística do saber. No âmbito da bioética (ética que trata da preservação de toda forma de vida), já não era mais possível crescer em sua área de conhecimento sem se perguntar pelas consequências desse desenvolvimento para o conjunto da criação. Recuperar uma visão holística da natureza e tomá-la não como um objeto, mas como um todo do qual fazemos parte, passaram a ser o mote da espiritualidade ecológica. Para Leonardo Boff, já é tempo de o ser humano se sentir filho da Mãe Terra e de se saber dentro dela com seus outros filhos, não como um ser que a transcende, tal qual o sujeito frente ao objeto, mas como um ser que se percebe ao perceber o meio do qual é parte integrante.

Numa abordagem mais biológica, embora alinhada à ecoteologia de Leonardo Boff, James Lovelock (1919), em seu texto A Vingança de

\footnotetext{
Cf. BOFF, Leonardo. Ecologia, Mundialização, Espiritualidade. Rio de Janeiro: Record, 2008, p. 79.

4 Cf. FOUCAULT, Michel. As Palavras e as Coisas. Tradução de Salma Tannus Muchail. São Paulo: Martins Fontes, 2007, p. 172.
} 
Gaia, posiciona a Terra como um organismo vivo prestes a expulsar toda e qualquer ameaça à sua saúde e integridade 5 . Contrariamente à interpretação tradicional de Gn 1, 26 - o ser humano não é externo à natureza, como se fosse seu senhor e dominador. Antes, como diz Lovelock, o ser humano é parte integrante desse organismo e, caso não venha a mudar sua conduta, corre o risco de ser expurgado por ele:

Na verdade, nem a fé em Deus, nem a confiança em deixar as coisas como estão, nem mesmo o compromisso com o desenvolvimento sustentável reconhecem nossa verdadeira dependência. Se deixarmos de cuidar da Terra, ela sem dúvida cuidará de si, fazendo com que não sejamos mais bem-vindos. Aqueles com fé devem reavaliar nosso lar terreno e vê-lo como um lugar sagrado, parte da criação divina, mas algo que temos profanado. ${ }^{6}$

Lovelock discorda da visão do laissez-faire (deixar as coisas seguirem seu fluxo natural) e nega a visão de que um desenvolvimento sustentável seja possível, embora isso tenha sido defendido por muitos pensadores. Duzentos anos atrás, quando a mudança era lenta ou inexistente, quiçá tivéssemos tempo de instituir um desenvolvimento sustentável ou de deixar as coisas como estavam, mas isso não mais cabe no tempo de crise ambiental que enfrentamos atualmente. "Esperar que o desenvolvimento sustentável ou a confiança em deixar as coisas como estão sejam políticas viáveis é como esperar que uma vítima de câncer no pulmão seja curada parando de fumar."

Tanto o desenvolvimento sustentável como o laissez-faire negam a doença da Terra causada pelo ser humano. Ambas advêm de crenças humanistas e religiosas que pensam a Terra como uma propriedade que pode ser explorada a favor da humanidade.

Creio que rejeitamos os sinais de que nosso mundo está mudando porque ainda somos, como nos lembrou aquele biólogo maravilhosamente sábio chamado E. O. Wilson, "carnivoros tribais". Estamos programados por nossa herança a ver os outros seres vivos sobretudo como algo comestivel, e nos importamos mais com nossa tribo nacional do que com qualquer outra coisa. Sacrificaremos até nossas vidas por ela e estamos dispostos a matar outros seres humanos, com a maior crueldade, em

5 Cf. LOVELOCK, James. A Vingança de Gaia. Tradução de Ivo Korytowski. Rio de Janeiro: Intrínseca, 2006.

6 LOVELOCK, 2006, p. 8.

7 LOVELOCK, 2006, p. 17. 
beneficio de nossa tribo. Ainda achamos estranho o conceito de que nós e o restante da vida, das bactérias às baleias, fazemos parte da entidade bem maior e mais diversa, a Terra viva. ${ }^{8}$

Segundo o autor, Gaia parece menos forte que no passado. O calor do sol vem aumentando gradualmente sobre ela, alterando sua autorregulação e colocando em risco todas as espécies de vida. Assim, parte significativa da humanidade está a caminho de destruir a si e a Terra, anulando a maioria das soluções alternativas que têm sido propostas, por inoperância, falta de vontade ou egoísmo mesmo. Enquanto vírus destruidor, se o ser humano não passar por uma verdadeira transformação, modificando seu modo de se relacionar com a biodiversidade, a Terra tratará de liquidá-lo para se proteger. É o que diz também o papa Francisco, apontando para a necessidade de passarmos por um processo de conversão ${ }^{9}$. Segundo ele, alguns cristãos, com o pretexto do realismo pragmático, se isentam do comprometimento com o meio ambiente e se tornam passivos e incoerentes ao se recusarem à mudança de hábitos e a passar por uma transformação radical de seu modus vivendi (metanoia). Se não conseguimos, pela compaixão, cuidar dos outros seres do planeta, compreendamos então que o cuidado com nós mesmos passa necessariamente pelo cuidado com esse outro que nos engloba (a Terra) e sem o qual fatidicamente perecerá a espécie humana. É preciso sair da autorreferencialidade e se autotranscender ${ }^{10}$. Mas, como falar em conversão num tempo avesso às práticas ascéticas? Pode essa expressão apresentar algum sentido para homens e mulheres contemporâneos?

\section{Cuidado de si e Conversão}

Michel Foucault (1926-1984), em suas pesquisas dedicadas ao cuidado de si na antiguidade clássica, trata do ascetismo ao estudar as formas de subjetivação e constituição do sujeito ético. É lugar comum o dito do filósofo francês: ninguém pode cuidar do outro se não sabe cuidar de si, ou, mais especificamente, ninguém pode governar o outro se não tem governo de si. Por outro viés, Foucault também abordará o tema da conversão. Desenvolvidas a partir do final dos anos 70 até o ano que

\footnotetext{
$8 \quad$ LOVELOCK, 2006, p. 17.

9 PAPAFRANCISCO. Laudato Si: sobre o cuidado com a casa comum. Carta Encíclica. Capítulo VI, § 202-208. São Paulo: Paulinas, 2015. 
antecedeu sua morte, as pesquisas do filósofo francês, ao buscar saídas para os assaltos do biopoder (poder sobre a vida), apontam para as técnicas de subjetivação operadas nos dois primeiros séculos de nossa era. Os resultados de seus estudos mostram que essas técnicas não estavam somente voltadas para o cuidado da cidade, como pensavam os gregos, mas constituíam o cerne mesmo daqueles que desejavam alcançar um grau maior em sua condição humana. Era assim que, nos séculos I e II de nossa era, estoicos e epicuristas concebiam o cuidado de si. Em suas diferentes formulações, o cuidado de si se apresentou como uma tarefa a cumprir. Em A Hermenêutica do Sujeito, curso ministrado no Collège de France nos primeiros meses de 1982, Foucault procura mostrar como o cuidado de si se relacionava ao conhecimento de si, e este, por sua vez, à verdade sobre si mesmo, não como algo posto, mas em constituição.

As pesquisas foucaultianas nos levaram a perceber que, diferentemente de Descartes e Kant, para os quais todo sujeito tem acesso direto à verdade, desde que obedeça às exigências do Cogito, o acesso à verdade para os antigos pedia a conversão do sujeito de conhecimento. Sem conversão, que implica um compromisso ético com o dizer verdadeiro (parresía), não é possível ter acesso à verdade:

É um traço geral, um principio fundamental, que o sujeito enquanto tal, do modo como é dado a si mesmo, não é capaz de verdade. E não é capaz de verdade, contudo, a não ser que efetue em si mesmo certas operações, certas transformações e modificações que o tornarão capaz da verdade. [...] Afora isto, porém, a ideia de uma conversão, por exemplo, como unicamente capaz de dar acesso à verdade, é encontrada em toda a filosofia antiga. Não podemos ter acesso à verdade se não mudamos nosso modo de ser. ${ }^{11}$

Segundo Foucault, esta transformação que o sujeito opera nele mesmo e por ele mesmo não pode ser efetuada sem um mestre que o ajude nessa tarefa. Todo cuidado de si passa necessariamente pelo outro. Foucault introduz o tema da parresía (palavra veraz) nos estudos sobre o cuidado de si quando faz a distinção entre formas de discurso na relação mestre e discípulo. Ele nos remete a Sêneca e às cartas deste a Lucílio. Nessas cartas, Sêneca mostra que o discurso lisonjeador é avesso ao cuidado de si, e lhe presta um mau favor, pois faz o outro acreditar que ele

11 FOUCAULT, Michel. A Hermenêutica do Sujeito. Curso ministrado no Collège de France (1981-1982). Tradução de Márcio Alves da Fonseca e Salma Tannus Muchail. São Paulo: Martins Fontes, 2006, p. 234. 
é melhor do que realmente é, negligenciando o cuidado de si. ${ }^{12}$ Foucault mostra como o discurso verdadeiro, parresía, passa a ser o discurso por excelência, uma vez que ele faz o discípulo crescer. Dá-se, assim, a relação entre cuidado de si, palavra veraz, conhecimento, verdade. Foucault discorre acerca dessa relação do sujeito cuidadoso de si com a verdade e mostra como, em Platão, ela está também ligada à espiritualidade:

Pois, também aí, considerando as coisas muito genericamente, ter acesso à verdade é ter acesso ao próprio ser, acesso este em que o ser ao qual se tem acesso será, ao mesmo tempo e em contraponto, o agente da transformação daquele que a ele tem acesso. É este o círculo platônico ou, em todo o caso, o círculo neoplatônico: conhecendo a mim mesmo, acedo a um ser que é a verdade, e cuja verdade transforma o ser que eu sou, assimilando-me a Deus. ${ }^{13}$

Posto que o tema da conversão em nossa sociedade é descartado em nome de uma racionalidade apartada de qualquer afinidade com a religião, a retomada dessa associação, trabalhada por um filósofo contemporâneo, é no mínimo interessante. Seguindo esse pensamento, a espiritualidade pleno desenvolvimento daquilo que constitui um determinado sujeito - está ligada, sobretudo, a esse acesso à verdade por meio de práticas ascéticas que conduzem, em última instância, o sujeito de conhecimento ao dizer verdadeiro (parresía) ${ }^{14}$. Por outro lado, a renúncia ascética, apregoada nas escolas gregas e romanas da antiguidade, contrariamente ao que viria a ser no cristianismo depois do IV século, não está relacionada à renúncia a si. Antes, será a renúncia a algo a que estamos ligados para adquirir outro bem de maior valor. Esse pensamento valoriza e alumia as palavras do papa Francisco ao citar o Patriarca Bartolomeu: "[Ele] propôs-nos passar do consumo ao sacrifício, da avidez à generosidade, do desperdício à capacidade de partilha, numa ascese que 'significa aprender a dar, e não simplesmente renunciar". ${ }^{15}$ Trata-se, portanto, de uma aquisição que o sujeito faz por sua própria vontade, e não uma renúncia à vontade pessoal. Viver a liberdade de filhos e filhas da mãe Terra, como diz Francisco de Assis, na comunhão com todas as criaturas e entoando todos os dias um cântico de agradecimento e de amor, só é possível se tivermos esse compromisso com o dizer verdadeiro, de tal modo que nossa forma de vida (forma vitae, como nos diz Giorgio

\footnotetext{
12 Cf. FOUCAULT, 2006, Aula de 10 de março, p. 450-460.

13 FOUCAULT, 2006, p. 236. p. 206.

14 Cf. FOUCAULT, Michel, 2008, Aula de 24 de fevereiro de 1982 (primeira hora), p. 351-380.

15 PAPA FRANCISCO, 2015, § 9, p. 9.
} 
Agamben) seja a expressão de uma vida veraz. Em tempos sombrios, quando a destruição da natureza é baseada na palavra falsa e nos dados falseados ${ }^{16}$, é um bom começo relacionar Ecologia a modos diferenciados de resistências. Estes encontram sua inspiração no dizer verdadeiro de Francisco de Assis, ao fazer do usus pauper uma forma de vida (forma vitae).

\section{Usus Pauper}

José Comblin (1923-2011), em A Profecia na Igreja, nos fala da presença ímpar de Francisco não só na Igreja, mas no mundo; não só para o contexto da Idade Média, mas em nosso contexto também. O teólogo belgo-brasileiro se volta para a pessoa de Francisco de Assis e sua época para neles buscar a inspiração necessária a um modo mais respeitoso e fraterno de lidarmos com os elementos da natureza. A forma extemporânea de Francisco de Assis, ao se relacionar com a natureza e o mundo, fora de seu tempo e por um tempo que há de vir, instaurou no seio da Igreja um despojamento e um respeito para com os elementos da Criação que estão alinhados aos mais recentes tratados de Ecologia. A linguagem poética de Francisco, ao tratar de forma fraterna os elementos da natureza, reverbera, como vimos, os resultados das mais recentes pesquisas que apresentam todos os seres vivos como partes desse imenso organismo vivo que é a Terra. Diferentemente dos monges de seu tempo, que tinham uma visão negativa do mundo, Francisco "celebrou a terra e os seus esplendores de modo positivo". ${ }^{17}$ Ele mostrou uma visão mais alegre e agradável do mundo, ainda que não fosse insensível aos seus aspectos negativos. No que diz respeito ao mundo dos homens, "percebeu que uma economia monetária permitia e promovia a acumulação de riqueza. O exemplo disso vinha-lhe do próprio pai"18. Comblin tem o

16 "Em entrevista ao semanário Brasil de fato, em $1^{\circ}$ de novembro de 2015, o ambientalista e membro do Fórum Nacional da Sociedade Civil nos Comitês de Bacias Hidrográficas (Fonasc), Gustavo Gazinelli, afirmava que a tragédia de Bento Rodrigues reavivou os debates sobre a fiscalização das atividades das mineradoras no Brasil. Entre eles, destaca-se o que envolve o novo Código de Mineração (PL 5807/13), que tramita em uma comissão especial da Câmara dos Deputados. Segundo Gazinelli, a maioria dos 31 deputados que compõem essa comissão, responsável por definir o marco legal para as atividades do setor no país, teve suas campanhas de 2014 financiadas por mineradoras. Para ele, o rompimento da Barragem do Fundão não traz novidade nenhuma, apenas desmascara todo o discurso de que as práticas de mineração são bem feitas, sustentáveis". (OTTAVIANI, Edelcio, 2016, p. 208-209)

17 COMBLIN, José. A Profecia na Igreja. 2. ed. São Paulo: Paulus, 2009, p. 137.

18 COMBLIN, 2009, p. 136. 
cuidado de não fazer de Francisco um teórico da exploração do capital avant la lettre, mas de mostrar como sua sensibilidade e sua capacidade em perceber os sinais dos tempos exigiam que se pensasse um modo de vida que não se deixasse regrar pelo dinheiro e pelo conjunto de verdades ditadas pelos mercadores. Comblin nos lembra, no entanto, o sofrimento do poverello com a divisão que atingiu seus irmãos de freternidade, gerando a corrente dos espirituais e dos conventuais. A grande questão que dividia os espirituais dos conventuais era o chamado usus pauper - uso pobre - das propriedades. Os espirituais defendiam um uso pobre e ponderado das propriedades, visto que a Ordem passou a ter muitos bens, por influência dos conventuais, que haviam requerido a construção de conventos e seminários para atender ao número crescente de adeptos. Muito embora tivesse havido resistência à propriedade dos bens, como os movimentos liderados por João Pedro Olivi (1248-1298) e (os) inspirados pelo monge calabrês Joaquim de Fiore (1132-1202), o usus pauper foi condenado no Concílio de Viena, em 1313, na mesma época em que o Papa João XXII começou a perseguir os espirituais. Em 1317 , por meio de uma bula que condenava os espirituais, muitos deles foram queimados vivos em Marseille, com o argumento de que Jesus possuía muitas propriedades e não seguia a pobreza praticada por eles.

É o filósofo Giorgio Agamben, no entanto, que elucidará as grandes questões que estavam latentes no debate sobre o usus pauper. Em Altíssima Pobreza, Agamben discorre, primeiramente, acerca da noção de usus, que caracteriza a polêmica orbitando o franciscanismo. Hugo de Digne e Boaventura procuraram demarcar a relação entre a propriedade privada e a pobreza. O primeiro parte dos estudos do direito romano e da lei natural, para afirmar que: "a lei natural prescreve aos homens que tenham uso das coisas necessárias para sua conservação, mas não os obriga de modo algum à propriedade" ${ }^{19}$. Daí a afirmação de que é possível renunciar à propriedade, mas ao uso, nunca e em lugar algum. ${ }^{20}$ Agamben ressalta que, por trás dessa afirmação, se esconde o "direito de não ter direito algum". ${ }^{21}$ Já Boaventura apresenta quatro tipos possíveis de relações com as coisas temporais: a propriedade, a posse, o usufruto e o simples uso. Citando a bula Quo elongati [Quanto mais afastados], de Gregório IX, Boaventura afirma que, com ela, o pontífice "separou a propriedade

19 APUD AGAMBEN, Altíssima Pobreza. São Paulo: Boitempo, 2014, p. 127.

20

Cf. AGAMBEN, 2014, p. 128.

21 Cf. AGAMBEN, 2014, p. 128. 
com relação ao uso [proprietatem separavit ab usu], mantendo para si e para a Igreja a propriedade e concedendo o uso para a necessidade dos frades" ${ }^{22}$. Em meio à disputa entre os conventuais e os espirituais, os primeiros escrevem sua Declaratio communitatis, na qual afirmam que a pobreza franciscana é exprimida através do usus facti-com a renúncia à propriedade - e não através do usus pauper - com a natureza intrínseca do uso - que era a intenção inicial dos franciscanos. Segundo Agamben, os espirituais franciscanos, ao manter a convicção de que poderia existir a separação entre aquele usus facti e a propriedade, apontavam para uma prática que desativava o próprio direito, pelo motivo de ela criar um vazio jurídico. O que interessa a Agamben, sobretudo ao estudar essa polêmica, é que, por trás da vontade dos espirituais em firmar o usus pauper, havia o desejo de fazer da pobreza uma forma de vida (espiritualidade). Não bastava abdicar da propriedade, mas se tratava de fazer do usus pauper das coisas uma forma de vida, e não o contrário. Para Francisco e os espirituais, contrariamente aos conventuais, não bastava abrir mão da propriedade e continuar a ter um uso "rico" das coisas. O que importava era manter não somente a desapropriação das coisas, mas também um uso contido - usus pauper - das mesmas. Sabemos, no entanto, que a conversão desse hábito não é fácil. Tratados e mais tratados racionais não são suficientes para que haja uma incitação à mudança de atitude. Francisco estaria a par disso? Intuitivamente acreditamos que sim. Eis o porquê de anunciar poeticamente seu evangelho da pobreza. Nietzsche já dizia que a função da arte é a de seduzir em favor da vida. Seria Francisco o grande sedutor que lançou mão da linguagem poética para nos seduzir a fazer da espiritualidade ecológica uma forma de vida? O próximo tópico procurará responder positivamente a essa questão.

\section{Linguagem Poética}

No início de sua Encíclica Laudato Si, o Papa Francisco cita o Cântico das Criaturas. Nele, a Terra é tida como uma irmã, com quem dividimos a vida, e como uma mãe acolhedora. Diferentemente do poverello, homem e mulher contemporâneos não se têm mostrado sensíveis para com nosso planeta. Laudato Si faz também referência aos pronunciamentos do Papa emérito Bento XVI, que lembrava ao mundo a importância de "eliminar as causas estruturais das disfunções da economia

22 BOAVENTURA. Apologia pauperum, XI, 5, p. 366, APUD AGAMBEN, 2014, p. 128. 
mundial e corrigir os modelos de crescimento que parecem incapazes de garantir o respeito ao meio ambiente" ${ }^{23}$. Um dos elementos que mais necessitam de nossa preservação é a água, essencialmente necessária a toda e qualquer forma de vida. ${ }^{24} \mathrm{~A}$ este elemento, Francisco de Assis dedicou uma estrofe de seu Cântico:

Louvado sejas, meu Senhor, pela irmã Água, que é mui útil e humilde e preciosa e casta.

Francisco de Assis, conforme o cântico, destaca quatro características do elemento água: utilidade, humildade, preciosidade e castidade, marcando a relação fraterna que possuía com esse elemento essencial à vida na Terra e nos inspirando a uma atitude transformadora para com a água. Francisco não hesita em atribuir qualidades antropológicas à água, a exemplo do profeta Daniel que exorta cada ser criado a louvar o Senhor Deus. No caso de Francisco, seu cântico é um louvor a Deus por suas criaturas.

Aágua é o elemento de maior utilidade dentre todos do planeta Terra. Ela é o elemento essencial a qualquer forma de vida, independentemente da espécie; alimenta os humanos e todos os outros animais e plantas; é fundamental para o equilíbrio de todos os ecossistemas; sacia nossa sede e faz crescer os nossos alimentos para que deles possamos nos nutrir. A água faz chover e se deixa alojar no menor dos espaços, alimenta os rios, lagos, oceanos e cachoeiras; purifica e umedece nosso ar, a atmosfera, os seres vivos e nossa casa comum por inteiro. Ela é arte: música da chuva, do mar e das cachoeiras. Aágua é livre e podemos usá-la para saciar nossas necessidades a qualquer tempo: assim, é preciso uma enorme força para aprisioná-la e fazer dela nossa propriedade. A natureza da água é própria para a liberdade; ela é maleável e pode escoar por qualquer brecha, por menor que seja. Francisco, devido à adesão à mentalidade do usus pauper, sentia a água como uma utilidade intrínseca à sua natureza, negando qualquer direito de propriedade que pudesse manifestar perante ela; não hesita em atribuir qualidades antropológicas à água, a exemplo do profeta Daniel que exorta cada ser criado a louvar o Senhor Deus. No caso da água, humildade e castidade são atributos da condição humana. Francisco, como veremos, projeta nesse elementos valores e virtudes próprios à concórdia entre os homens e os estende à concórdia (sentir com o mesmo coração) em toda a Criação. A humildade, conforme o descrito no texto Escritos e

23 Cf. AGAMBEN, 2014, p. 128.

24 Cf. PAPA FRANCISCO, 2015, § 27-47. 
biografias de São Francisco de Assis, era uma das mais marcantes atribuições do poverello, prevista em seu comportamento, no seu porte e nos seus costumes. A humildade está intrinsecamente ligada a todas as virtudes, sendo um pré-requisito para mantê-las.

A seu entender, [ele próprio, Francisco] não passava de um pecador, apesar de ser brilho e esplendor de toda espécie de santidade. Tratou sempre de edificar a si mesmo sobre a humildade, colocando o fundamento que tinha aprendido de Cristo. Esquecido dos lucros que tinha tido, só sabia ver os próprios defeitos, olhando mais o que faltava do que o que possuía. Seu único desejo era ser melhor, para juntar novas virtudes sem se contentar com as que já tinha. Era humilde de presença, mais humilde de sentimento e muito mais humilde no modo de pensar. ${ }^{25}$

Essa virtude, presente na Idade Média e na Idade Moderna, diz respeito ao espírito de serviço, lembrando que Francisco desejava com todo o seu coração servir a Deus na humildade e na pobreza. "Da raiz hum vem homo, humanus, e humilis. O homem (homo), tomado da terra (humus), vive conforme sua constituição, é humilis no sentido mais amplo."26 Essa mesma água entrega-se ao serviço na Terra, dá-se abundante para manter todas as formas de vida e permite que a manifestação de Deus em todos os seres do nosso planeta se perpetue. Aágua serve a todos os seres do planeta, independentemente de raça, etnia, religião, cultura, etc. Ela se mistura com todos sem se importar com qualquer uma dessas características. A humildade da água faz a justiça, pois, qualquer que seja o recipiente que a aprisione, estará nivelada. Aágua se faz humilde, pois escorre até as camadas mais baixas do nosso planeta até fundir-se com o oceano. Isso, é claro, sem esquecer que a água não se faz mais presente a todos os seres da sociedade devido a problemas decorrentes de sua privatização - oposto do uso.

Aágua é o bem mais precioso que nos foi concedido. Como Al Gore nos relembrou, ela é a maior constituinte de nosso corpo físico - $71 \%$ do nosso corpo é água. Devemos a ela nossa existência e nossa permanência no planeta. A cada gole de água que ingerimos e a cada alimento vivo que a Terra nos oferece, deveríamos nos sentir gratos e reconhecer tamanha preciosidade da água, porque ela nos mantém vivos em cada um desses atos. Talvez não reconheçamos tamanha preciosidade por conta de ela ser o elemento mais abundante em todo o nosso planeta, mas não podemos nos esquecer de que ela também é o mais importante. A água é tão preciosa

25 VV. AA. Escritos e Biografias de São Francisco de Assis. Petrópolis, RJ: Vozes, 1986, p. 386 .

26 FRIES, Heinrich. Dicionário de Teologia: Conceitos Fundamentais da Teologia Atual. Vol. 2. 2. ed. São Paulo: Edições Loyola, 1983, p. 343. 
exatamente por ser tão útil e tão humilde. De nada adianta ser extremamente útil quando não se tem humildade a ponto de ser acessível a todos. Ela é um bem da Natureza, e não um mero produto do ser humano. Aágua é tão preciosa, que o planeta Terra é um dos únicos que tem a felicidade de contê-la. Por isso, temos o dever de administrar bem o nosso sistema hídrico planetário, para que tamanha preciosidade seja mantida.

A castidade da água dá-se devido à sua pureza, à sua limpidez, à sua transparência, mas também "à integridade das forças vitais e de amor depositadas nela". ${ }^{27} \mathrm{~A}$ água não tem cor, não tem forma, não tem cheiro e nem gosto. Ela não se apega a nenhuma imagem, serve a todos igualmente. Em estado natural, não existe nenhum tipo de mácula na água e não deveríamos maculá-la justamente por isso. É o princípio da reciprocidade e do reconhecimento dos valores mútuos, base da justiça comutativa: como ela nos é essencial, à medida que mais necessitamos dela, maior deveria ser nosso respeito para com ela. Por comportar o aspecto da liberdade, a água reflete o aprendizado do domínio de si, que comanda suas paixões e estabelece a paz. ${ }^{28}$

A água não tem gula, e ninguém tem gula por água, nossa sede acaba à medida que nossa necessidade pela água é suprida. Não existe avareza na água, e não deveríamos possuir avareza por ela, lembrando que ela é bem mais abundante em nosso planeta e que, se a conservarmos bem, nunca faltará. A água não possui luxúria, e somente temos prazer com ela na medida em que ela nos é útil, ou seja, na medida em que ela nos sacia. A água não tem ira, e até mesmo nas suas formas mais selvagens, como na água do mar e das cachoeiras, pode acalmar qualquer um, seja com suas carícias ou com sua música. E se por acaso ela se mostra terrível como em um tsunami, isso se deve a um movimento involuntário do qual ela não tem responsabilidade e, por isso, não podemos lhe imputar nenhuma culpa. A água não possui inveja e ninguém possui inveja dela. $\mathrm{Na}$ água, não existe preguiça; sua natureza é o movimento, o fluxo. Não existe orgulho na água; sua natureza é a humildade.

A água casta não está contaminada de nenhum modo pelo ser humano. Quando bem conservada, ela nunca se estraga ou perde suas funções. Entretanto, quando ela é aprisionada na civilização, é contaminada pelos vícios humanos, é poluída, torna-se densa e turva. O mau uso

27 Cf. CONGREGAÇÃO PARA A DOUTRINA DA FÉ. Catecismo da Igreja Católica, § 2338. Disponível em: <http//www.catequisar.com.br/dw/catecismo.pdf>. Acesso em 23 jul. 2016. 
que fazemos da água, devido à nossa mentalidade exploradora, destrói a castidade desse fundamental elemento.

À guisa de conclusão, podemos dizer que este breve ensaio teve por objetivo ressaltar a intuição do papa Francisco em nos mostrar, na Laudato $\mathrm{Si}$, a necessidade de estabelecermos um cuidado permanente com a mãe Terra; a urgente conversão de nossa sede de possuir, consumir e dominar, e, de forma poética, o respeito particular que todos devemos ter para com o elemento predominante nesta bela casa comum: a Terra, o planeta água.

\section{Referências}

AGAMBEN. Altíssima Pobreza. São Paulo: Boitempo, 2014.

BOFF, Leonardo. Ecologia, Mundialização, Espiritualidade. Rio de Janeiro: Record, 2008, p. 79.

COMBLIN, José. A Profecia na Igreja. 2. ed. São Paulo: Paulus, 2009. CONGREGAÇÃO PARA A DOUTRINA DA FÉ. Catecismo da Igreja Católica, § 2338. Disponível em: <http//www.catequisar.com.br/dw/ catecismo.pdf $>$. Acesso em: 23 jul. 2016.

FOUCAULT, Michel. As Palavras e as Coisas. Tradução de Salma Tannus Muchail. São Paulo: Martins Fontes, 2007, p. 172.

. Curso Ministrado no Collège de France (1981-1982). Tradução de Márcio Alves da Fonseca e Salma Tannus Muchail. São Paulo: Martins Fontes, 2006.

FRIES, Heinrich. Dicionário de Teologia: Conceitos Fundamentais da Teologia Atual. Vol. 2, 2. ed. São Paulo: Loyola, 1983.

LOVELOCK, James. A Vingança de Gaia. Tradução de Ivo Korytowski. Rio de Janeiro: Intrínseca, 2006.

OTTAVIANI, Edelcio. Doença, convalescença e ascese, o que suporta um corpo: notas sobre o cuidado com a mãe Terra, nossa casa comum. Revista de Cultura Teológica, São Paulo, ano XXIV, n. 87, jan/jun 2016, p. 202-230.

PAPA FRANCISCO. Laudato Si: sobre o cuidado com a casa comum. Carta Encíclica. Capítulo VI, § 202-208. São Paulo: Paulinas, 2015.

VV. AA. Escritos e Biografias de São Francisco de Assis. Petrópolis: Vozes, 1986.

\section{E-mail do autor:} edelcioottaviani@hotmail.com 